\title{
Understanding of COPD among final-year medical students
}

This article was published in the following Dove Press journal:

International Journal of COPD

Javier Mohigefer'

Carmen Calero-Acuña ${ }^{2,3}$

Eduardo Marquez-Martin²

Francisco Ortega-Ruiz ${ }^{2,3}$

Jose Luis Lopez-Campos ${ }^{2,3}$

'Faculty of Medicine, ${ }^{2}$ MedicalSurgical Unit of Respiratory Diseases, Instituto de Biomedicina de Sevilla (IBiS), Hospital Universitario Virgen del Rocío, Universidad de Sevilla, Seville, ${ }^{3} \mathrm{CIBER}$ de Enfermedades Respiratorias (CIBERES), Instituto de Salud Carlos III, Madrid, Spain
Correspondence: Javier Mohigefer Hospital Universitario Virgen del Rocío, Universidad de Sevilla, Avenida Manuel Siurot, s/n, 41013 Seville, Spain Email javi5r@hotmail.com
Objective: Several previous studies have shown a suboptimal level of understanding of COPD among different population groups. Students in their final year of Medicine constitute a population that has yet to be explored. The evaluation of their understanding provides an opportunity to establish strategies to improve teaching processes. The objective of the present study is to determine the current level of understanding of COPD among said population.

Methods: A cross-sectional observational study was done using digital surveys given to medical students in their final year at the Universidad de Sevilla. Those surveyed were asked about demographic data, smoking habits as well as the clinical manifestation, diagnosis and treatment of COPD.

Results: Of the 338 students contacted, responses were collected from 211 of them (62.4\%). Only $25.2 \%$ had an accurate idea about the concept of the disease. The study found that $24.0 \%$ of students were familiar with the three main symptoms of COPD. Tobacco use was not considered a main risk factor for COPD by $1.5 \%$ of students. Of those surveyed, $22.8 \%$ did not know how to spirometrically diagnose COPD. Inhaled corticosteroids were believed to be part of the main treatment for this disease among $51.0 \%$ of the students. Results show that $36.4 \%$ of respondents believed that home oxygen therapy does not help COPD patients live longer. Only $15.0 \%$ considered the Body-mass index, airflow Obstruction, Dyspnea, and Exercise (BODE) index to be an important parameter for measuring the severity of COPD. Giving up smoking was not believed to prevent worsening COPD among 3.4\% of students surveyed. Almost half of students $(47.1 \%)$ did not recommend that those suffering from COPD undertake exercise.

Conclusion: The moderate level of understanding among the population of medical students in their final year shows some strengths and some shortcomings. Teaching intervention is required to reinforce solid knowledge among this population.

Keywords: COPD, knowledge, surveys and questionnaires, students, medical

\section{Introduction}

COPD, a disease characterized by persistent respiratory symptoms and airflow limitation due to airway and/or alveolar abnormalities usually caused by significant exposure to noxious particles or gases, ${ }^{1}$ is one of the diseases with the greatest impact on world health. There are currently an estimated 328 million people suffering from COPD around the world. ${ }^{2}$ The Global Burden of Disease Study underscores that COPD was the sixth leading cause of death in 1990, has been the fourth since 2000 and is expected to be the third by $2020 .{ }^{3}$ Furthermore, the underdiagnosis of COPD poses a major challenge. In the EPI-SCAN study, $73 \%$ of individuals with irreversible airflow obstruction compatible with COPD were not diagnosed. ${ }^{4}$

In this context, it is important for both the population and health professionals to have a good knowledge about this disease as a necessary step to avoiding such high 
underdiagnostic percentages. Unfortunately, the available evidence suggests that the lack of knowledge about the disease is high among a variety of populations. Studies have been done among patients with varying conditions, ${ }^{5}$ among patients with COPD, ${ }^{6,7}$ among doctors ${ }^{8}$ and among the general population, ${ }^{9}$ demonstrating suboptimal knowledge about COPD.

Studying disease understanding among final-year medical student population constitutes an especially relevant line of research for public health as it allows us to understand this population's notions about the disease, which will help to identify weaknesses and, at the same time, allow us to design strategies for health education among this population. In the case of COPD, this information is especially relevant given its importance in epidemiology, clinical manifestation and health management. ${ }^{10}$ Furthermore, the study of the medical student population represents an especially relevant niche since they have recently studied the disease and are close to receiving a license to practice medicine in society. ${ }^{11}$

The benefits of the population having appropriate knowledge about the disease are clear. On one hand, for the general population, doctor-patient contact is made sooner, increasing the likelihood of earlier treatment with a potential impact on disease prognosis. ${ }^{12}$ On the other hand, for students, better education implies lower underdiagnosis, better control and better information for the patients about their disease.

One population that has yet to be explored in this sense is that of medical students. Specifically, students in the final year of Medicine constitute an especially interesting population in the study of knowledge about the disease as they have recently studied the disease and will receive a license to practice medicine in society in a few months. However, until now, medical students' knowledge about COPD has never been evaluated. Consequently, the objective of this study is to analyze the knowledge final-year medical students have about this disease.

The results of this study will give us the opportunity to take a closer look at the level of knowledge the students have regarding this disease and help to identify areas of improvement and to establish strategies to improve teaching for this disease.

\section{Methods}

This is a cross-sectional observational study which was done using a survey about the understanding of COPD among a population of medical students in their final year at the Universidad de Sevilla (348 students). Per protocol, we set 200 surveys (58\% of the total number of students) as the appropriate limit to obtain an adequate number of surveys to allow us to explore the current situation, keeping in mind an estimated loss of $8 \%$ due to surveys which were incorrectly completed or considered incomplete.

\section{Survey content}

The questions included on the survey were selected based on previous papers published about knowledge surveys ${ }^{5,9,13}$ and based on the research team's experience and knowledge about the disease (Supplementary material). The format of the questions differed according to the objective of each item. The survey included the following types of questions: multiple choice, true/false, Likert-type scales from 0 to 10 and open questions. The questions were divided into six sections: sociodemographic data about the respondent, the concept of COPD, clinical manifestation, diagnosis, nonpharmacological treatment, and pharmacological treatment. Among the sociodemographic data, respondents were asked about their degree of affinity for Pneumology, being asked to rate it on a scale of $0-10$ with 10 being the greatest affinity. The questions about diagnosis were aimed at covering three concepts: the need for the spirometric criterion forced expiratory volume in 1 second $\left(\mathrm{FEV}_{1}\right)$ /forced vital capacity $<0.7$ to diagnose obstruction, evaluating the severity of the obstruction with spirometry, and evaluating the severity according to the Global Initiative for Obstructive Lung Disease (GOLD) ${ }^{1}$ and the national Spanish guidelines for COPD management (GesEPOC) documents. ${ }^{14}$

For true/false and multiple-choice questions, $80 \%$ correct or higher was considered a suitable result. There were three open questions: briefly define what COPD is, list the main risk factors for COPD, and list the primary symptoms of COPD. To analyze the first, the minimum elements that should appear in the answer were identified in order to consider it valid. In this way, respondents were required to identify three ideas: tobacco exposure, irreversible bronchial obstruction, and pulmonary disease. Expressing the meaning of the acronym COPD, was also evaluated. The definition was considered correct if the three concepts appeared and incorrect if one was missing, and it was noted if the answer was missing two or more concepts but the meaning of the acronym COPD was correctly defined. In the case of the second question, which requires a list, a weighted description of the different indicated answers was made. For the last question, we evaluated whether the three main symptoms (cough, expectoration and dyspnea) were identified and, at the same time, we studied what symptom was described most frequently. 


\section{Data collection}

The survey was done using the Google Forms tool (Google, Mountain View, CA, USA). Once the survey was created, the URL to access it was sent to the target population using the messaging application WhatsApp (Facebook, Inc., Menlo Park, CA, USA). The period for data collection was December 26, 2015, through February 26, 2016. During this time, a reminder was sent to those students who had not yet responded every two weeks. Participation was voluntary, confidential and anonymous.

\section{Ethics}

This study was carried out in accordance with the principles of the Declaration of Helsinki for research involving human subjects. During the study, no personal data were collected about the participants in the study which would allow them to be identified. The data obtained was kept strictly confidential (Spanish Organic Law 15/1999 on the protection of personal data), and only the principal investigator for the project had access to it. Each case was anonymized and numbered with a code to guarantee data confidentiality. Ethical approval was granted by the Research Ethics Committee of the University Hospitals Virgen MacarenaVirgen del Rocío. Before initially completing the survey, students accessed an information sheet (Supplementary material) which specified that the survey was being done in the context of a research project and the answers would not influence their final grade as students. Accordingly, the participants provided informed consent for participation in the survey.

\section{Statistical analysis}

The quality of the data was evaluated before completing a statistical analysis. To do so, we transferred the data to the program IBM SPSS Statistics version 24.0 (IBM Corporation, Armonk, NY, USA). The quality analysis of data was done variable by variable, searching for missing, extreme and inconsistent values. Those surveys which were considered to be of insufficient quality were excluded from the analysis. Once the final database was obtained, a descriptive analysis of data was done using the absolute and relative frequencies for the categorical variables and the mean and standard variation in parentheses for the continuous variables. Comparison between groups (gender, tobacco use and affinity) for the subject was done using the chi-square test. In cases of $2 \times 2$ tables, the Fisher exact test was applied when the expected frequencies were less than 5 in one of the categories. To study the influence of active tobacco use on the results, habitual and occasional smokers were categorized as active smokers. Comparisons on the importance of the different diseases were done by using the unpaired $t$-test. The $\alpha$ error was set at 0.05 .

\section{Results}

\section{Sociodemographic data}

The selection of completed surveys is shown in Figure 1. The study population comprised 348 medical students, of whom $211(60.6 \%)$ completed the survey. After evaluating the quality of the surveys, five were discarded. Consequently, there remained 206 surveys. Participants were students, primarily females $(62.6 \%)$, and had an average age of 23.3 (0.7) years. With regard to habitual tobacco use, the sample included 167 (81.1\%) participants who had never smoked, nine (4.4\%) former smokers, 19 (9.2\%) occasional smokers and $11(5.3 \%)$ habitual smokers. In terms of affinity for the subject, the sample comprised $30(14.6 \%)$ respondents with a high affinity, $112(54.4 \%)$ with an intermediate affinity, and $64(31.1 \%)$ with a low affinity.

\section{Concept of COPD}

The results for the survey items referring to the concept of COPD are summarized in Table 1 . Only $25.2 \%$ were able to correctly define the disease. Although before beginning the degree $72.9 \%$ had heard of the disease through different means (primarily the media, doctors and the Internet), only $17 \%$ admitted they were familiar with it before beginning their studies.

Those surveyed classified COPD as the second most severe disease after ischemic heart disease. The stance on the anti-smoking law was appropriate with a very favorable stance

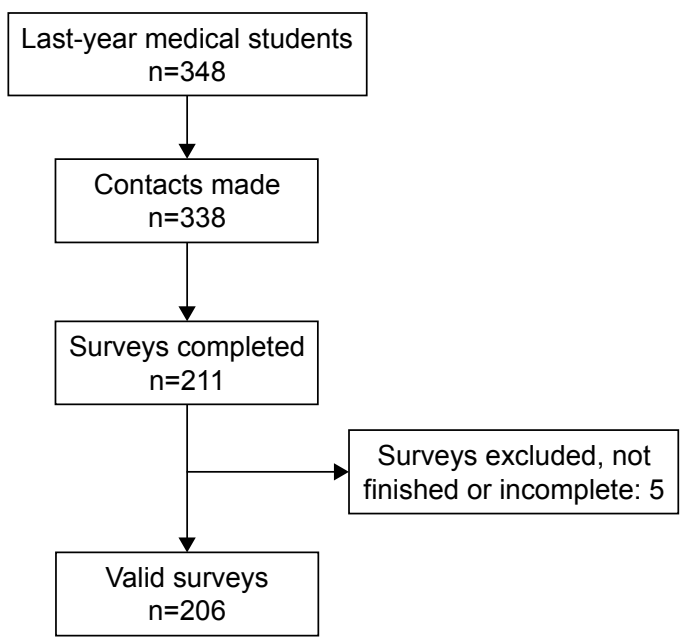

Figure I Selection of surveys 
Table I Survey results regarding understanding of COPD

\begin{tabular}{|c|c|c|c|c|c|c|c|c|}
\hline \multirow[t]{2}{*}{ Variable } & \multirow{2}{*}{$\begin{array}{l}\text { Total } \\
(n=206)\end{array}$} & \multicolumn{2}{|l|}{ Gender } & \multicolumn{2}{|c|}{ Active smoker } & \multicolumn{3}{|l|}{ Affinity } \\
\hline & & $\begin{array}{l}\text { Female } \\
(n=129)\end{array}$ & $\begin{array}{l}\text { Male } \\
(n=77)\end{array}$ & $\begin{array}{l}\text { No } \\
(n=\mid 76)\end{array}$ & $\begin{array}{l}\text { Yes } \\
(n=30)\end{array}$ & $\begin{array}{l}\text { High } \\
(n=30)\end{array}$ & $\begin{array}{l}\text { Medium } \\
(n=I \mid 2)\end{array}$ & $\begin{array}{l}\text { Low } \\
(n=64)\end{array}$ \\
\hline \multicolumn{9}{|l|}{ Definition of COPD } \\
\hline Correct definition & $52(25.2)$ & $35(27.1)$ & $17(22.1)$ & $43(24.4)$ & $9(30.0)$ & $10(33.3)$ & $25(22.3)$ & $17(26.6)$ \\
\hline Incorrect or incomplete definition & $115(55.8)$ & $71(55.0)$ & $44(57.1)$ & $98(55.7)$ & $17(56.7)$ & $13(43.3)$ & $64(57.1)$ & $38(59.4)$ \\
\hline Define acronym & $39(18.9)$ & $23(17.8)$ & $16(20.8)$ & 35 (19.9) & $4(13.3)$ & $7(23.3)$ & $23(20.5)$ & $9(14.1)$ \\
\hline Familiar with COPD before studies & $35(17.0)$ & $17(13.2)$ & $18(23.4)$ & $29(16.5)$ & $6(20.0)$ & $6(20.0)$ & $20(17.9)$ & $9(14.1)$ \\
\hline \multicolumn{9}{|l|}{ Means of hearing about COPD } \\
\hline a) Media & $4 \mathrm{I}(19.9)$ & $25(19.4)$ & $16(20.8)$ & $34(19.3)$ & $7(23.3)$ & $6(20.0)$ & $25(22.3)$ & $10(15.6)$ \\
\hline b) Doctors & $39(18.9)$ & $23(17.8)$ & $16(20.8)$ & 35 (19.9) & $4(13.3)$ & $9(30.0)$ & $19(17.0)$ & II (I7.2) \\
\hline c) Internet & $37(18.0)$ & $24(18.6)$ & $13(16.9)$ & $31(17.6)$ & $6(20.0)$ & $9(30.0)$ & $22(19.6)$ & $6(9.4)^{*}$ \\
\hline d) Relative or acquaintance with disease & $28(13.6)$ & $17(13.2)$ & II (14.3) & $19(10.8)$ & $9(30.0)^{*}$ & $2(6.7)$ & $16(14.3)$ & $10(15.6)$ \\
\hline e) Pharmacists & $2(1.0)$ & $0(0)$ & $2(2.6)$ & $0(0)$ & $2(6.7)$ & $0(0)$ & I (0.9) & I (I.6) \\
\hline f) Other & $3(1.5)$ & $2(1.6)$ & $\mathrm{I}(1.3)$ & $3(1.7)$ & $0(0)$ & $2(6.7)^{*}$ & $\mathrm{I}(0.9)$ & $0(0)$ \\
\hline \multicolumn{9}{|c|}{ On a scale of 0 (not serious) to 10 (maximum severity), indicate how serious you believe the following illnesses to be } \\
\hline a) COPD & $7.8(1.0)$ & $8.0(0.8)$ & $7.6(1.1)^{*}$ & $7.9(0.8)$ & $7.6(1.5)$ & $7.9(0.8)$ & $8.0(0.8)^{*}$ & $7.5(1.2)$ \\
\hline b) Diabetes mellitus & $7.7(1.3)$ & $7.8(1.1)$ & $7.5(1.5)$ & $7.8(1.2)$ & $7.4(1.5)$ & $8.0(0.9)$ & $7.8(1.1)$ & $7.4(1.6)$ \\
\hline c) Arterial hypertension $\neq$ & $7.3(1.4)$ & $7.5(1.1)$ & $7.1(1.7)^{*}$ & $7.4(1.3)$ & $7.0(1.8)$ & $7.6(1.1)$ & $7.4(1.2)$ & $6.9(1.6)$ \\
\hline d) Angina pectoris ${ }^{\ddagger}$ & $8.4(1.0)$ & $8.5(0.9)$ & $8.3(1.2)$ & $8.5(0.9)$ & $8.1(1.4)$ & $8.9(0.7)^{*}$ & $8.4(0.8)$ & $8.3(1.3)$ \\
\hline e) Stomach ulcer ${ }^{\ddagger}$ & $6.5(1.4)$ & $6.7(1.1)$ & $6.2(1.7)^{*}$ & $6.5(1.3)$ & $6.4(1.6)$ & $6.3(1.6)$ & $6.6(1.3)$ & $6.3(1.3)$ \\
\hline f) Arthrosis/arthritis ${ }^{\ddagger}$ & $5.9(1.4)$ & $6.1(1.2)$ & $5.7(1.6)^{*}$ & $5.9(1.4)$ & $6.0(1.4)$ & $6.1(1.2)$ & $6.1(1.3)$ & $5.7(1.5)$ \\
\hline \multicolumn{9}{|l|}{ Stance on the anti-smoking law } \\
\hline a) Against & $3(1.5)$ & $\mathrm{I}(0.8)$ & $2(2.6)$ & $2(1.1)$ & I (3.3) & $0(0)$ & $2(1.8)$ & $\mathrm{I}(\mathrm{I} .6)$ \\
\hline b) In favor & $40(19.4)$ & $21(16.3)$ & $19(24.7)$ & $30(17.0)$ & $10(33.3)^{*}$ & $7(23.3)$ & $20(17.9)$ & $13(20.3)$ \\
\hline c) Highly in favor & $162(78.6)$ & $107(82.9)$ & $55(71.4)$ & $143(81.3)$ & $19(63.3)^{*}$ & $23(76.7)$ & $90(80.4)$ & $49(76.6)$ \\
\hline d) Do not know & I $(0.5)$ & $0(0)$ & $\mathrm{I}(\mathrm{I} .3)$ & I $(0.6)$ & $0(0)$ & $0(0)$ & $0(0)$ & I (I.6) \\
\hline Familiar with the national strategy for COPD & $70(34.0)$ & $43(33.3)$ & $27(35.1)$ & $64(36.4)$ & $6(20.0)$ & $13(43.3)$ & $43(38.4)$ & $14(21.9)^{*}$ \\
\hline \multicolumn{9}{|l|}{ Content of the strategy for COPD } \\
\hline a) Not familiar & $145(70.4)$ & $92(7 \mid .3)$ & $53(68.8)$ & $121(68.8)$ & $24(80.0)$ & $18(60.0)$ & $72(64.3)$ & $55(85.9)^{*}$ \\
\hline b) More or less familiar & $52(25.2)$ & $29(22.5)$ & $23(29.9)$ & $46(26.1)$ & $6(20.0)$ & $8(26.7)$ & $36(32.1)^{*}$ & $8(12.5)^{*}$ \\
\hline c) Fairly familiar & $9(4.4)$ & $8(6.2)$ & $\mathrm{I}(\mathrm{I} .3)$ & $9(5.1)$ & $0(0)$ & $4(13.3)^{*}$ & $4(3.6)$ & I ( $(1.6)$ \\
\hline \multicolumn{9}{|l|}{ COPD risk factors } \\
\hline Tobacco & $203(98.5)$ & $128(99.2)$ & $75(97.4)$ & $175(99.4)$ & $28(93.3)^{*}$ & $28(93.3)^{*}$ & $112(100)$ & $63(98.4)$ \\
\hline Genetics & $67(32.5)$ & $38(29.5)$ & $29(37.7)$ & $60(34.1)$ & $7(23.3)$ & $9(30.0)$ & $38(33.9)$ & $20(31.3)$ \\
\hline Environmental pollution & $49(23.8)$ & $31(24.0)$ & $18(23.4)$ & $39(22.2)$ & $10(33.3)$ & $4(13.3)$ & $27(24.1)$ & $18(28.1)$ \\
\hline Occupational exposure & $18(8.7)$ & $8(6.2)$ & $10(13.0)$ & $15(8.5)$ & $3(10.0)$ & $2(6.7)$ & $9(8.0)$ & $7(10.9)$ \\
\hline Bronchial hyperresponsiveness & $5(2.4)$ & $4(3.1)$ & $\mathrm{I}(\mathrm{I} .3)$ & $4(2.3)$ & $\mathrm{I}(3.3)$ & I (3.3) & $3(2.7)$ & $\mathrm{I}(\mathrm{I} .6)$ \\
\hline $\begin{array}{l}\text { Biological pathways contributing to } \\
\text { pathogenesis of COPD (number) }\end{array}$ & $3.8(2.6)$ & $3.5(2.5)$ & $4.3(2.8) *$ & $3.7(2.5)$ & $4.6(3.2)$ & $3.9(2.7)$ & $4.0(2.8)$ & $3.5(2.4)$ \\
\hline Not familiar with any biological pathway & $31(15.0)$ & $23(17.8)$ & $8(10.4)$ & $25(14.2)$ & $6(20.0)$ & $2(6.7)$ & $18(16.1)$ & II (I7.2) \\
\hline
\end{tabular}

Notes: Results are expressed as absolute (relative) frequency or mean (standard deviation), according to the nature of the variable. $* p<0.05$ for comparison between groups. ${ }^{\ddagger} p<0.05$ for comparison between diseases.

among active smokers (63.3\%) and nonsmokers (81.3\%), this difference being significant. There was also an association between familiarity with the national strategy for COPD as well as its content and an affinity for the subject ( $p=0.042$ and $p=0.003$, respectively). None of those surveyed listed the five risk factors for COPD. A relationship was observed between smokers and nonsmokers with regard to identifying tobacco use as a risk factor for COPD (Table 1).

Due to lack of knowledge, $15 \%$ decided not to respond to the question about the contributing biological pathways. The most commonly indicated biological pathway was the participation of inflammatory mediators (proteins) (46.6\%), followed by an increase in inflammatory cells (46.1\%) and respiratory infections $(42.2 \%)$.

\section{Clinical manifestation}

The results for the survey items referring to the clinical manifestation of COPD are summarized in Table 2. Of the students surveyed, 34\% recognized the symptomatology of the disease (cough, expectoration and dyspnea). With regard to these three symptoms, dyspnea was the answer most frequently given by respondents $(80.6 \%)$. Only $37.9 \%$ knew 
Table 2 Survey results regarding clinical manifestations of COPD

\begin{tabular}{|c|c|c|c|c|c|c|c|c|}
\hline \multirow[t]{2}{*}{ Variable } & \multirow{2}{*}{$\begin{array}{l}\text { Total } \\
(n=206)\end{array}$} & \multicolumn{2}{|l|}{ Gender } & \multicolumn{2}{|c|}{ Active smoker } & \multicolumn{3}{|l|}{ Affinity } \\
\hline & & $\begin{array}{l}\text { Female } \\
(n=129)\end{array}$ & $\begin{array}{l}\text { Male } \\
(n=77)\end{array}$ & $\begin{array}{l}\text { No } \\
(n=\mid 76)\end{array}$ & $\begin{array}{l}\text { Yes } \\
(n=30)\end{array}$ & $\begin{array}{l}\text { High } \\
(n=30)\end{array}$ & $\begin{array}{l}\text { Medium } \\
(n=I \mid 2)\end{array}$ & $\begin{array}{l}\text { Low } \\
(n=64)\end{array}$ \\
\hline Clinical manifestation of COPD (includes three symptoms) & $70(34.0)$ & $46(35.7)$ & $24(3 \mid .2)$ & $61(34.7)$ & $9(30.0)$ & $9(30.0)$ & $38(33.9)$ & $23(35.9)$ \\
\hline Dyspnea & $166(80.6)$ & $108(83.7)$ & $58(75.3)$ & $142(80.7)$ & $24(80.0)$ & $25(83.3)$ & $87(77.7)$ & $54(84.4)$ \\
\hline Cough & $140(68.0)$ & $91(70.5)$ & $49(63.6)$ & $119(67.6)$ & $21(70.0)$ & $23(76.7)$ & $69(61.6)$ & $48(75.0)$ \\
\hline Expectoration & $78(37.9)$ & $54(41.9)$ & $24(3 \mid .2)$ & $66(37.5)$ & $12(40.0)$ & $9(30.0)$ & $44(39.3)$ & $25(39.1)$ \\
\hline \multicolumn{9}{|l|}{ About the diagnosis of chronic bronchitis and emphysema } \\
\hline $\begin{array}{l}\text { a) The diagnosis of chronic bronchitis is clinical and that } \\
\text { of emphysema is anatomopathological (correct) }\end{array}$ & III (53.9) & $79(6 \mathrm{I} .2)^{*}$ & $32(4 \mid .6)$ & $94(53.4)$ & $17(56.7)$ & $16(53.3)$ & $61(54.5)$ & $34(53.1)$ \\
\hline $\begin{array}{l}\text { b) The diagnosis of chronic bronchitis is } \\
\text { anatomopathological and that of emphysema is clinical }\end{array}$ & $10(4.9)$ & $4(3.1)$ & $6(7.8)$ & $8(4.5)$ & $2(6.7)$ & I (3.3) & $5(4.5)$ & $4(6.3)$ \\
\hline $\begin{array}{l}\text { c) The diagnosis of chronic bronchitis and emphysema is } \\
\text { clinical }\end{array}$ & 76 (36.9) & $45(34.9)$ & $31(40.3)$ & $66(37.5)$ & $10(33.3)$ & $12(40.0)$ & $44(39.3)$ & $20(31.3)$ \\
\hline $\begin{array}{l}\text { d) The diagnosis of chronic bronchitis and emphysema is } \\
\text { anatomopathological }\end{array}$ & $8(3.9)$ & $\mathrm{I}(0.8)$ & $7(9.1)^{*}$ & $7(4.0)$ & I (3.3) & I (3.3) & $2(1.8)$ & $5(7.8)$ \\
\hline $\begin{array}{l}\text { Centriacinar emphysema is related to tobacco use, while } \\
\text { panacinar emphysema is related to an } \alpha \text { I-antitrypsin } \\
\text { deficit }\end{array}$ & $176(85.4)$ & $112(86.8)$ & $64(83.1)$ & $149(84.7)$ & $27(90.0)$ & $25(83.3)$ & $92(82.1)$ & $59(92.2)$ \\
\hline $\begin{array}{l}\text { If a patient diagnosed with COPD refers to wheezing, the } \\
\text { diagnosis must be reconsidered as this is surely a sign of } \\
\text { asthma (false) }\end{array}$ & $169(82.0)$ & $108(83.7)$ & 61 (79.2) & I43 (8I.3) & $26(86.7)$ & $21(70.0)$ & $98(87.5)^{*}$ & $50(78.1)$ \\
\hline
\end{tabular}

Notes: Results are expressed as absolute (relative) frequencies. ${ }^{*} p<0.05$ for comparison between groups.

that expectoration is a symptom of COPD. The identification of chronic bronchitis as a clinical finding and emphysema as a morphological finding was correctly made by just over half of the respondents, mostly females. Interestingly, 76 (36.9\%) of those surveyed responded that both chronic bronchitis and emphysema are clinical concepts.

\section{Diagnosis}

The results for the survey items referring to the diagnosis of COPD are summarized in Table 3. Although the diagnostic criteria were identified by the majority of participants, the evaluation of obstruction severity with spirometry or according to current documents was fairly poor, being worse among men and active smokers. The questions about the degree of obstruction in spirometry were answere correctly by approximately $50 \%$, and the questions about the GOLD document classification were answered correctly by $65 \%$, while severity evaluation according to GesEPOC was correctly done by less than $20 \%$. When a case of obstruction with $\mathrm{FEV}_{1}>80 \%$ was presented, $83(40.3 \%)$ respondents answered that the patient did not suffer from COPD as there was no obstruction. Furthermore, 102 (49.5) participants confused moderate and severe COPD. With regard to the clinical phenotypes of COPD, those surveyed identified more phenotypes than those recognized in the GesEPOC document. ${ }^{14}$ As for the evaluation of severity, 141 (68.4\%) respondents indicated that the severity according to GesEPOC is determined by the $\mathrm{FEV}_{1}$.

\section{Non-pharmacological treatment}

The results for the survey items referring to non-pharmacological treatment are summarized in Table 4. With regard to nonpharmacological treatment, $80 \%$ of successful answers was only achieved in two questions: the importance of giving up smoking and pneumococcal vaccination. However, the recommendations regarding exercise and the indication for oxygen therapy had a lower response. The indication for oxygen therapy was confused with the concept of respiratory distress by $64(31.1 \%)$ respondents.

\section{Pharmacological treatment}

The results for the survey items referring to pharmacological treatment are summarized in Table 5 . The exploratory questions about pharmacological treatment had a correct response rate far from $80 \%$, with the exception of the question about not abandoning treatment when symptoms improve. A higher affinity for the subject correlates to the correct use of corticosteroids ( $p=0.033$ ) as well as the appropriate use of long-acting bronchodilators during exacerbations ( $p=0.038$ ). It is worrying that $105(51.0 \%)$ of those surveyed thought a combination of inhaled corticosteroid (ICS) and long-acting $\beta_{2}$-agonist was the primary pharmacological treatment for COPD. 
Table 3 Survey results regarding the diagnosis of COPD

\begin{tabular}{|c|c|c|c|c|c|c|c|c|}
\hline \multirow[t]{2}{*}{ Variable } & \multirow{2}{*}{$\begin{array}{l}\text { Total } \\
(n=206)\end{array}$} & \multicolumn{2}{|l|}{ Gender } & \multicolumn{2}{|c|}{ Active smoker } & \multicolumn{3}{|l|}{ Affinity } \\
\hline & & $\begin{array}{l}\text { Female } \\
(n=\mid 29)\end{array}$ & $\begin{array}{l}\text { Male } \\
(n=77)\end{array}$ & $\begin{array}{l}\text { No } \\
(n=\mid 76)\end{array}$ & $\begin{array}{l}\text { Yes } \\
(n=30)\end{array}$ & $\begin{array}{l}\text { High } \\
(n=30)\end{array}$ & $\begin{array}{l}\text { Medium } \\
(n=|| 2)\end{array}$ & $\begin{array}{l}\text { Low } \\
(n=64)\end{array}$ \\
\hline $\begin{array}{l}\text { A current or former smoker with a cough and } \\
\text { chronic expectoration should be diagnosed with }\end{array}$ & $198(96.1)$ & $124(96.1)$ & $74(96.1)$ & $169(96.0)$ & $29(96.7)$ & $29(96.7)$ & $107(95.5)$ & $62(96.9)$ \\
\hline \multicolumn{9}{|l|}{ COPD without performing any additional tests (false) } \\
\hline \multicolumn{9}{|l|}{ In spirometry, COPD is diagnosed by } \\
\hline a) $\mathrm{FEV}_{\text {, }}$ & $42(20.4)$ & $29(22.5)$ & $13(16.9)$ & $36(20.5)$ & $6(20.0)$ & $6(20.0)$ & $27(24.1)$ & $9(14.1)$ \\
\hline b) $\mathrm{FEV}_{\mathrm{I}} / \mathrm{FVC}<0.7$ (correct) & $159(77.2)$ & $98(76.0)$ & $61(79.2)$ & I $37(77.8)$ & $22(73.3)$ & $23(76.7)$ & $83(74.1)$ & $53(82.8)$ \\
\hline c) MMEF $25 / 75<60 \%$ & $2(1.0)$ & I $(0.8)$ & I ( 1.3$)$ & $2(I . I)$ & $0(0)$ & I (3.3) & I (0.9) & $0(0)$ \\
\hline d) FVC $<80 \%$ & $2(1.0)$ & $0(0)$ & $2(2.6)$ & $\mathrm{I}(0.6)$ & I (3.3) & $0(0)$ & I (0.9) & $\mathrm{I}(\mathrm{I} .6)$ \\
\hline \multicolumn{9}{|c|}{ If a COPD patient has a bronchial obstruction detected in the spirometry with $\mathrm{FEV},>80 \%$, it is COPD with functional limitation which is } \\
\hline a) It is not COPD, there is no obstruction & $83(40.3)$ & $48(37.2)$ & $35(45.5)$ & $69(39.2)$ & $14(46.7)$ & $15(50.0)$ & $45(40.2)$ & $23(35.9)$ \\
\hline b) Mild (correct) & $113(54.9)$ & $78(60.5)$ & $35(45.5)^{*}$ & $99(56.3)$ & 14 (46.7) & $15(50.0)$ & $63(56.3)$ & $35(54.7)$ \\
\hline c) Moderate & $3(1.5)$ & $0(0)$ & $3(3.9)^{*}$ & $3(1.7)$ & $0(0)$ & $0(0)$ & $2(1.8)$ & $\mathrm{I}(\mathrm{I} .6)$ \\
\hline d) Severe & $4(1.9)$ & $2(1.6)$ & $2(2.6)$ & $3(1.7)$ & I (3.3) & $0(0)$ & $\mathrm{I}(0.9)$ & $3(4.7)$ \\
\hline \multicolumn{9}{|c|}{ If a COPD patient has a bronchial obstruction detected in the spirometry with $\mathrm{FEV}$, between $30 \%$ and $50 \%$, it is COPD with functional limitation which is } \\
\hline a) It is not COPD, there is no obstruction & $\mathrm{I}(0.5)$ & $0(0)$ & I (I.3) & I (0.6) & $0(0)$ & I (3.3) & $0(0)$ & $0(0)$ \\
\hline b) Mild & $2(1.0)$ & $\mathrm{I}(0.8)$ & $\mathrm{I}(\mathrm{l} .3)$ & $2(1.1)$ & $0(0)$ & $\mathrm{I}(3.3)$ & $\mathrm{I}(0.9)$ & $0(0)$ \\
\hline c) Moderate & $102(49.5)$ & $69(53.5)$ & $33(42.9)$ & $81(46.0)$ & $21(70.0) *$ & $12(40.0)$ & $61(54.5)$ & $29(45.3)$ \\
\hline d) Severe (correct) & $99(48.1)$ & $58(45.0)$ & $4 \mid(53.2)$ & 91 (5I.7) & $8(26.7)^{*}$ & $16(53.3)$ & $50(44.6)$ & $33(51.6)$ \\
\hline COPD is a progressive disease but spirometry & $156(75.7)$ & $94(72.9)$ & $62(80.5)$ & $133(75.6)$ & $23(76.7)$ & $23(76.7)$ & $86(76.8)$ & $47(73.4)$ \\
\hline \multicolumn{9}{|l|}{ readings can return to normal with intensive } \\
\hline \multicolumn{9}{|c|}{ treatment and giving up smoking (false) } \\
\hline \multicolumn{9}{|c|}{ A patient diagnosed with COPD who has an $\mathrm{FEV}$, of $60 \%$ with frequent symptoms and one exacerbation in the last year belongs to GOLD group } \\
\hline a) GOLD A & $25(12.1)$ & $13(10.1)$ & $12(15.6)$ & $21(11.9)$ & $4(13.3)$ & $3(10.0)$ & II (9.8) & II (17.2) \\
\hline b) GOLD B (correct) & $132(64.1)$ & $83(64.3)$ & $49(63.6)$ & $116(65.9)$ & $16(53.3)$ & $23(76.7)$ & $75(67.0)$ & $34(53.1)^{*}$ \\
\hline c) GOLD C & $44(21.4)$ & $30(23.3)$ & $14(18.2)$ & $36(20.5)$ & $8(26.7)$ & $3(10.0)$ & $24(21.4)$ & $17(26.6)$ \\
\hline d) GOLD D & $2(1.0)$ & I (0.8) & I (I.3) & $2(1.1)$ & $0(0)$ & $\mathrm{I}(3.3)$ & I (0.9) & $0(0)$ \\
\hline \multicolumn{9}{|c|}{ Indicate which of these clinical phenotypes are currently recognized in the regulations (check all that apply) } \\
\hline a) Exacerbated phenotype with chronic bronchitis & $156(75.7)$ & $100(77.5)$ & $56(72.7)$ & $134(76.1)$ & $22(73.3)$ & $24(80.0)$ & 87 (77.7) & $45(70.3)$ \\
\hline b) Exacerbated phenotype with emphysema & $153(74.3)$ & $95(73.6)$ & $58(75.3)$ & I3I (74.4) & $22(73.3)$ & $26(86.7)$ & $82(73.2)$ & $45(70.3)$ \\
\hline c) Mixed COPD phenotype with asthma & $118(57.3)$ & $77(59.7)$ & $4 I(53.2)$ & $100(56.8)$ & $18(60.0)$ & $16(53.3)$ & $66(58.9)$ & $36(56.3)$ \\
\hline d) Non-exacerbated phenotype & $90(43.7)$ & $57(44.2)$ & $33(42.9)$ & $72(40.9)$ & $18(60.0)$ & $13(43.3)$ & $5 I(45.5)$ & $26(40.6)$ \\
\hline e) COPD phenotype with heart disease & $58(28.2)$ & $37(28.7)$ & $21(27.3)$ & $52(29.5)$ & $6(20.0)$ & $5(16.7)$ & $36(32.1)$ & $17(26.6)$ \\
\hline f) Phenotype with OSA & $58(28.2)$ & $41(31.8)$ & $17(22.1)$ & $53(30.1)$ & $5(16.7)$ & $6(20.0)$ & $36(32.1)$ & $16(25.0)$ \\
\hline g) Phenotype with bronchiectasis & $55(26.7)$ & $31(24.0)$ & $24(31.2)$ & $48(27.3)$ & $7(23.3)$ & $9(30.0)$ & $29(25.9)$ & $17(26.6)$ \\
\hline h) Phenotype with pulmonary fibrosis & $53(25.7)$ & $33(25.6)$ & $20(26.0)$ & $46(26.1)$ & $7(23.3)$ & $3(10.0)^{*}$ & $30(26.8)$ & $20(31.3)$ \\
\hline \multicolumn{9}{|c|}{ The main parameter for measuring COPD severity according to the Spanish guide on COPD (GesEPOC) } \\
\hline a) $\mathrm{FEV}_{1}$ & $|4|(68.4)$ & $94(72.9)$ & $47(61.0)$ & $123(69.9)$ & $18(60.0)$ & $22(73.3)$ & $79(70.5)$ & $40(62.5)$ \\
\hline b) Dyspnea & $24(I I .7)$ & $12(9.3)$ & $12(15.6)$ & $19(10.8)$ & $5(16.7)$ & $4(13.3)$ & $16(14.3)$ & $4(6.3)$ \\
\hline c) BODE (correct) & $31(15.0)$ & $19(14.7)$ & $12(15.6)$ & $25(14.2)$ & $6(20.0)$ & $3(10.0)$ & $15(13.4)$ & $13(20.3)$ \\
\hline d) Ability to exercise & $9(4.4)$ & $4(3.1)$ & $5(6.5)$ & $8(4.5)$ & I (3.3) & I (3.3) & $2(1.8)$ & $6(9.4)$ \\
\hline
\end{tabular}

Notes: Results are expressed as absolute (relative) frequencies. ${ }^{*} p<0.05$ for comparison between groups.

Abbreviations: BODE, Body-mass index, airflow Obstruction, Dyspnea, and Exercise; FEV , forced expiratory volume in I second; FVC, forced vital capacity; MMEF, maximal mid-expiratory flow; GOLD, Global Initiative for Obstructive Lung Disease; OSA, obstructive sleep apnea.

\section{Discussion}

This study provides information regarding knowledge about COPD among the population of medical students in their final year of study. The results indicate a moderate level of understanding among this population with notable areas of improvement including aspects regarding diagnosis, characterization and the treatment of patients suffering from the disease. Additionally, this moderate level of understanding is slightly influenced by the respondents' gender, tobacco use, and affinity for respiratory diseases in some of the aspects evaluated.

There are similar previous experiences in the general population. Specifically, two previous studies have been done in Spain at the national level, ${ }^{9,15}$ both in the national sphere and among general population. Of these, the CONOCEPOC study ${ }^{9}$ recently obtained a total of 6,528 surveys at a $13.1 \%$ 
Table 4 Survey results regarding non-pharmacological treatment

\begin{tabular}{|c|c|c|c|c|c|c|c|c|}
\hline \multirow[t]{2}{*}{ Variable } & \multirow{2}{*}{$\begin{array}{l}\text { Total } \\
(n=206)\end{array}$} & \multicolumn{2}{|l|}{ Gender } & \multicolumn{2}{|c|}{ Active smoker } & \multicolumn{3}{|l|}{ Affinity } \\
\hline & & $\begin{array}{l}\text { Female } \\
(n=129)\end{array}$ & $\begin{array}{l}\text { Male } \\
(n=77)\end{array}$ & $\begin{array}{l}\text { No } \\
(n=176)\end{array}$ & $\begin{array}{l}\text { Yes } \\
(n=30)\end{array}$ & $\begin{array}{l}\text { High } \\
(n=30)\end{array}$ & $\begin{array}{l}\text { Medium } \\
(n=1 \mid 2)\end{array}$ & $\begin{array}{l}\text { Low } \\
(n=64)\end{array}$ \\
\hline Giving up smoking prevents worsening COPD (true) & $199(96.6)$ & $126(97.7)$ & $73(94.8)$ & $169(96.0)$ & $30(100)$ & $30(100)$ & $107(95.5)$ & $62(96.9)$ \\
\hline Oxygen therapy increases survival (true) & $|3|(63.6)$ & $81(62.8)$ & $50(64.9)$ & $110(62.5)$ & $21(70.0)$ & $23(76.7)$ & $68(60.7)$ & $40(62.5)$ \\
\hline \multicolumn{9}{|l|}{ The indications for home oxygen therapy are } \\
\hline a) $\mathrm{PaO}_{2} \leq 60 \mathrm{mmHg}$ or $\mathrm{SatO}_{2} \leq 92 \%$ & $64(31.1)$ & $38(29.5)$ & $26(33.8)$ & $50(28.4)$ & $14(46.7)^{*}$ & $8(26.7)$ & $36(32.1)$ & $20(31.3)$ \\
\hline b) $\mathrm{PaO}_{2} \leq 55 \mathrm{mmHg}$ or $\mathrm{SatO}_{2} \leq 88 \%$ (correct) & $86(41.7)$ & $58(45.0)$ & $28(36.4)$ & $77(43.8)$ & $9(30.0)$ & I $3(43.3)$ & $46(4 I . I)$ & $27(42.2)$ \\
\hline c) $\mathrm{PaO}_{2} \leq 50 \mathrm{mmHg}$ or $\mathrm{SatO}_{2} \leq 84 \%$ & $37(18.0)$ & $18(14.0)$ & $19(24.7)$ & $30(17.0)$ & $7(23.3)$ & $7(23.3)$ & $21(18.8)$ & $9(14.1)$ \\
\hline d) $\mathrm{PaO}_{2} \leq 45 \mathrm{mmHg}$ or $\mathrm{SatO}_{2} \leq 80 \%$ & $17(8.3)$ & $14(10.9)$ & $3(3.9)$ & $17(9.7)$ & $0(0)$ & $2(6.7)$ & $8(7.1)$ & $7(10.9)$ \\
\hline \multicolumn{9}{|l|}{ With regard to vaccines and COPD } \\
\hline $\begin{array}{l}\text { a) A pneumococcal I3-valent conjugate vaccine and } \\
\text { annual flu vaccine are recommended (correct) }\end{array}$ & $173(84.0)$ & $104(80.6)$ & $69(89.6)$ & $150(85.2)$ & $23(76.7)$ & $29(96.7)$ & $89(79.5)$ & $55(85.9)$ \\
\hline b) Only an annual flu vaccine is recommended & $24(11.7)$ & $20(15.5)^{*}$ & $4(5.2)$ & $21(11.9)$ & $3(10.0)$ & $0(0)^{*}$ & $18(16.1)^{*}$ & $6(9.4)$ \\
\hline $\begin{array}{l}\text { c) If the patient has not had pneumonia, no vaccines are } \\
\text { necessary }\end{array}$ & $0(0)$ & $0(0)$ & $0(0)$ & $0(0)$ & $0(0)$ & $0(0)$ & $0(0)$ & $0(0)$ \\
\hline $\begin{array}{l}\text { d) Vaccinations are not recommended due to } \\
\text { immunosuppression in these patients }\end{array}$ & $2(1.0)$ & $0(0)$ & $2(2.6)$ & I (0.6) & I (3.3) & I (3.3) & $0(0)$ & I ( $(1.6)$ \\
\hline All COPD patients should be encouraged to exercise (true) & $109(52.9)$ & $65(50.4)$ & $44(57.1)$ & $97(55.1)$ & $12(40.0)$ & $14(46.7)$ & $61(54.5)$ & $34(53.1)$ \\
\hline
\end{tabular}

Notes: Results are expressed as absolute (relative) frequencies. $*_{p}<0.05$ for comparison between groups.

Table 5 Survey results regarding pharmacological treatment

\begin{tabular}{|c|c|c|c|c|c|c|c|c|}
\hline \multirow[t]{2}{*}{ Variable } & \multirow{2}{*}{$\begin{array}{l}\text { Total } \\
(n=206)\end{array}$} & \multicolumn{2}{|l|}{ Gender } & \multicolumn{2}{|c|}{ Active smoker } & \multicolumn{3}{|l|}{ Affinity } \\
\hline & & $\begin{array}{l}\text { Female } \\
(n=129)\end{array}$ & $\begin{array}{l}\text { Male } \\
(\mathrm{n}=77)\end{array}$ & $\begin{array}{l}\text { No } \\
(n=176)\end{array}$ & $\begin{array}{l}\text { Yes } \\
(n=30)\end{array}$ & $\begin{array}{l}\text { High } \\
(n=30)\end{array}$ & $\begin{array}{l}\text { Medium } \\
(n=I / 2)\end{array}$ & $\begin{array}{l}\text { Low } \\
(n=64)\end{array}$ \\
\hline Salbutamol can always be used as a rescue medication (true) & $|2|(58.7)$ & $81(62.8)$ & $40(51.9)$ & $104(59.1)$ & $17(56.7)$ & $17(56.7)$ & $67(59.8)$ & $37(57.8)$ \\
\hline \multicolumn{9}{|c|}{ The primary pharmacological treatment for COPD is } \\
\hline a) Short-acting bronchodilators & $8(3.9)$ & $5(3.9)$ & $3(3.9)$ & $5(2.8)$ & $3(10.0)$ & I (3.3) & $4(3.6)$ & $3(4.7)$ \\
\hline b) Long-acting bronchodilators & $88(42.7)$ & $59(45.7)$ & $29(37.7)$ & $80(45.5)$ & $8(26.7)$ & $13(43.3)$ & $49(43.8)$ & $26(40.6)$ \\
\hline c) Inhaled corticosteroids with a long-acting $\beta_{2}$-agonist & $105(51.0)$ & $61(47.3)$ & $44(57.1)$ & $88(50.0)$ & $17(56.7)$ & $16(53.3)$ & $56(50.0)$ & $33(51.6)$ \\
\hline d) Theophylline & $5(2.4)$ & $4(3.1)$ & $\mathrm{I}(\mathrm{I} .3)$ & $3(1.7)$ & $2(6.7)$ & $0(0)$ & $3(2.7)$ & $2(3.1)$ \\
\hline $\begin{array}{l}\text { Patients can stop using long-acting inhalers when COPD } \\
\text { symptoms improve (false) }\end{array}$ & $157(76.2)$ & $97(75.2)$ & $60(77.9)$ & $136(77.3)$ & $21(70.0)$ & $24(80.0)$ & $90(80.4)$ & $43(67.2)$ \\
\hline \multicolumn{9}{|c|}{ The pharmacological treatment used for non-exacerbated COPD in GOLD stage $C$ should be } \\
\hline a) LABA + LAMA + inhaled corticosteroids & $69(33.5)$ & $50(38.8) *$ & $19(24.7)$ & $59(33.5)$ & $10(33.3)$ & $9(30.0)$ & $37(33.0)$ & $23(35.9)$ \\
\hline b) LABA + inhaled corticosteroids & $83(40.3)$ & $46(35.7)$ & $37(48.1)$ & $73(41.5)$ & $10(33.3)$ & $14(46.7)$ & $47(42.0)$ & $22(34.4)$ \\
\hline c) LABA or LAMA & $16(7.8)$ & $7(5.4)$ & $9(11.7)$ & $14(8.0)$ & $2(6.7)$ & $2(6.7)$ & $9(8.0)$ & $5(7.8)$ \\
\hline d) LABA + LAMA (correct) & $35(17.0)$ & $24(18.6)$ & II (14.3) & $28(15.9)$ & $7(23.3)$ & $5(16.7)$ & $18(16.1)$ & $12(18.8)$ \\
\hline \multicolumn{9}{|c|}{$\begin{array}{l}\text { Inhaled corticosteroids are indicated for COPD in patients with frequent exacerbations in spite of correct bronchodilator treatment or in the mixed } \\
\text { phenotype with asthma }\end{array}$} \\
\hline $\begin{array}{l}\text { a) Exclusively for patients with frequent exacerbations in } \\
\text { spite of correct bronchodilator treatment }\end{array}$ & $4 I(19.9)$ & $25(19.4)$ & $16(20.8)$ & $37(21.0)$ & $4(13.3)$ & $5(16.7)$ & $21(18.8)$ & $15(23.4)$ \\
\hline b) All cases of patients with severe COPD & $21(10.2)$ & $10(7.8)$ & II (14.3) & $15(8.5)$ & $6(20.0)$ & $2(6.7)$ & $13(11.6)$ & $6(9.4)$ \\
\hline $\begin{array}{l}\text { c) For patients with frequent exacerbations in spite of } \\
\text { correct bronchodilator treatment or in the mixed } \\
\text { phenotype with asthma (correct) }\end{array}$ & $96(46.6)$ & $64(49.6)$ & $32(41.6)$ & $81(46.0)$ & $15(50.0)$ & $18(60.0)$ & $59(52.7)$ & $19(29.7)^{*}$ \\
\hline $\begin{array}{l}\text { d) Very symptomatic patients in spite of treatment with } \\
\text { a long-acting bronchodilator }\end{array}$ & $43(20.9)$ & $27(20.9)$ & $16(20.8)$ & $39(22.2)$ & $4(13.3)$ & $5(16.7)$ & $17(15.2)$ & $21(32.8)$ \\
\hline $\begin{array}{l}\text { If a COPD patient has an exacerbation, his or her long- } \\
\text { acting bronchodilators should be substituted for high-dosage } \\
\text { short-acting bronchodilators during the exacerbation (false) }\end{array}$ & $112(54.4)$ & $75(58.1)$ & $37(48.1)$ & $95(54.0)$ & I 7 (56.7) & $16(53.3)$ & $69(61.6)^{*}$ & $27(42.2)^{*}$ \\
\hline
\end{tabular}

Notes: Results are expressed as absolute (relative) frequencies. ${ }^{*} p<0.05$ for comparison between groups.

Abbreviations: GOLD, Global Initiative for Obstructive Lung Disease; LABA, long-acting $\beta_{2}$-agonist; LAMA, long-acting muscarinic agonist. 
response rate with representation from every region of the country. Although there is a similar percentage of active smokers (habitual and occasional) in both studies $(19.4 \%$ in CONOCEPOC vs $14.5 \%$ in the present study) with a similar evaluation of COPD severity (8.3 points in CONOCEPOC vs 7.8 in the present study), some of the results differ. In the general population, the main means of hearing about the disease is through the media (39.8\% in CONOCEPOC). However, in our sample, although still the main means, this percentage is considerably lower (19.9\%) with a slight difference from other surveyed sources of information. The spontaneous knowledge about COPD evaluated by CONOCEPOC $(17.0 \%)$ could not be verified in our case as spontaneous knowledge has not been analyzed. However, only $44.1 \%$ of respondents knew the correct concept or were able to identify the meaning of the acronym COPD. The identification of the respiratory symptoms associated with the disease (dyspnea, cough and expectoration) was similar to the general population in the CONOCEPOC study $(81.1 \%, 29.0 \%$ and $10.6 \%$, respectively). The fact that in a population like ours only $37.9 \%$ identified expectoration as part of the clinical manifestation of the disease stands out. Finally, the stance on the anti-smoking law was similar in both studies, with a considerable improvement in knowledge about the national strategy for COPD in our survey $(4.7 \%$ vs $34.0 \%)$.

The results of subgroup analysis should be treated with caution. This study was not intended to evaluate the differences between groups, and the results are thus informative. With regard to the gender of respondents, men showed worse identification of the concepts of chronic bronchitis and emphysema and worse identification of mild COPD by spirometry. However, they tended to recommend triple therapy more frequently. The overprescription of triple therapy for COPD treatment currently constitutes a problem in managing the disease in diverse areas of health care. In this sense, this overuse of triple therapy has recently been described in all stages of the disease, ${ }^{16}$ including as an initial treatment. ${ }^{17}$ Given that ICSs are not innocuous and their side effects are dose-dependent, there is an international call for the rational use of these pharmaceuticals in COPD treatment. ${ }^{18}$

In terms of tobacco use, active smokers (habitual and occasional) were less likely to be in favor of the anti-smoking law, less commonly identified tobacco use as a risk factor for COPD and less correctly identified severe COPD by spirometry. These data seem to suggest a different attitude toward the disease. These results reinforce the need to transmit the relationship between tobacco use and COPD to the population in order for tobacco users to be aware of the potential effects tobacco use has on respiratory health. Recently, the literature has indicated that even low-intensity smokers have a higher mortality risk than nonsmokers. ${ }^{19}$ With regard to affinity for the subject, those surveyed who indicated a high affinity heard about the disease through the Internet more frequently and provided better answers to some of the survey questions; an expected result.

In the light of these findings, it follows that initiatives for improvement in undergraduate medical education are always welcome. Different initiatives including reinforcing concepts or problem-based learning can be alternatives available for this purpose. ${ }^{20,21}$

To correctly interpret our results, some methodological considerations must be kept in mind. Participation in the survey was voluntary which may imply a selection bias. Although the study was not based on a study population sample to guarantee the representiveness of the selected sample, the response rate provides a sample size that suggests that the data presented may be a reflection of the reality for students at our university. On the other hand, given the intrinsic limitations in completing a survey, the number of evaluated concepts was limited. Finally, this survey was done at a specific university within a geographical framework and set time frame. It would be ideal for future studies to confirm our findings in other geographic areas and to be completed over time in order to identify teaching processes to improve knowledge about the disease among future doctors.

\section{Conclusion}

Our final-year medical students identify COPD as a serious disease, and the evaluation of their knowledge about COPD highlights some areas of improvement. This study identifies the main weaknesses in diagnosis, clinical characterization and treatment. We hope these results will be useful to improve university teaching which will help in appropriately preparing doctors to diagnose and treat COPD in the community.

\section{Acknowledgments}

The authors would like to thank the final-year students at the Faculty of Medicine, Universidad de Sevilla, during the academic year 2015-2016, for their generous participation in this study.

\section{Disclosure}

The authors report no conflicts of interest in this work. 


\section{References}

1. Vogelmeier CF, Criner GJ, Martínez FJ, et al. Global Strategy for the Diagnosis, Management, and Prevention of Chronic Obstructive Lung Disease 2017 report: GOLD executive summary. Arch Bronconeumol. 2017;53(3):128-149.

2. Vos T, Flaxman AD, Naghavi M, et al. Years lived with disability (YLDs) for 1160 sequelae of 289 diseases and injuries 1990-2010: a systematic analysis for the Global Burden of Disease Study 2010. Lancet. 2012;380(9859):2163-2196.

3. Murray CJ, Lopez AD. Alternative projections of mortality and disability by cause 1990-2020: Global Burden of Disease Study. Lancet. 1997;349(9064):1498-1504.

4. Miravitlles M, Soriano JB, García-Río F, et al. Prevalence of COPD in Spain: impact of undiagnosed COPD on quality of life and daily life activities. Thorax. 2009;64(10):863-868.

5. de Queiroz MC, Moreira MA, Jardim JR, et al. Knowledge about COPD among users of primary health care services. Int J Chron Obstruct Pulmon Dis. 2014;10:1-6.

6. Ray SM, Helmer RS, Stevens AB, Franks AS, Wallace LS. Clinical utility of the chronic obstructive pulmonary disease knowledge questionnaire. Fam Med. 2013;45(3):197-200.

7. White R, Walker P, Roberts S, Kalisky S, White P. Bristol COPD Knowledge Questionnaire (BCKQ): testing what we teach patients about COPD. Chron Respir Dis. 2006;3(3):123-131.

8. Davis KJ, Landis SH, Oh YM, et al. Continuing to Confront COPD International Physician Survey: physician knowledge and application of COPD management guidelines in 12 countries. Int J Chron Obstruct Pulmon Dis. 2014;10:39-55.

9. Soriano JB, Calle M, Montemayor T, Álvarez-Sala JL, Ruiz-Manzano J, Miravitlles M. The general public's knowledge of chronic obstructive pulmonary disease and its determinants: current situation and recent changes. Arch Bronconeumol. 2012;48(9):308-315.

10. López-Campos JL, Tan W, Soriano JB. Global burden of COPD. Respirology. 2016;21(1):14-23.
11. Griffin MF, Hindocha S. Publication practices of medical students at British medical schools: experience, attitudes and barriers to publish. Med Teach. 2011;33(1):e1-e8.

12. Welte T, Vogelmeier C, Papi A. COPD: early diagnosis and treatment to slow disease progression. Int J Clin Pract. 2015;69(3):336-349.

13. Wong CK, Yu WC. Correlates of disease-specific knowledge in Chinese patients with COPD. Int J Chron Obstruct Pulmon Dis. 2016;11:2221-2227.

14. Miravitlles M, Soler-Cataluña JJ, Calle M, et al. Spanish guidelines for management of chronic obstructive pulmonary disease (GesEPOC) 2017. Pharmacological treatment of stable phase. Arch Bronconeumol. 2017;53(6):324-335.

15. Miravitlles M, de la Roza C, Morera J, et al. Chronic respiratory symptoms, spirometry and knowledge of COPD among general population. Respir Med. 2006;100(11):1973-1980.

16. Brusselle G, Price D, Gruffydd-Jones K, et al. The inevitable drift to triple therapy in COPD: an analysis of prescribing pathways in the UK. Int J Chron Obstruct Pulmon Dis. 2015;10:2207-2217.

17. Simeone JC, Luthra R, Kaila S, et al. Initiation of triple therapy maintenance treatment among patients with COPD in the US. Int $J$ Chron Obstruct Pulmon Dis. 2016;12:73-83.

18. Hinds DR, DiSantostefano RL, Le HV, Pascoe S. Identification of responders to inhaled corticosteroids in a chronic obstructive pulmonary disease population using cluster analysis. BMJ Open. 2016;6(6):e010099.

19. Inoue-Choi M, Liao LM, Reyes-Guzman C, Hartge P, Caporaso N, Freedman ND. Association of long-term, low-intensity smoking with all-cause and cause-specific mortality in the National Institutes of Health-AARP Diet and Health Study. JAMA Intern Med. 2017; 177(1):87-95.

20. Nendaz MR, Tekian A. Assessment in problem-based learning medical schools: a literature review. Teach Learn Med. 1999;11(4):232-243.

21. Dolmans DHJM, Loyens SMM, Marcq H, Gijbels D. Deep and surface learning in problem-based learning: a review of the literature. $A d v$ Health Sci Educ Theory Pract. 2016;21(5):1087-1112.
International Journal of COPD

\section{Publish your work in this journal}

The International Journal of COPD is an international, peer-reviewed journal of therapeutics and pharmacology focusing on concise rapid reporting of clinical studies and reviews in COPD. Special focus is given to the pathophysiological processes underlying the disease, intervention programs, patient focused education, and self management protocols.

\section{Dovepress}

This journal is indexed on PubMed Central, MedLine and CAS. The manuscript management system is completely online and includes a very quick and fair peer-review system, which is all easy to use. Visit $\mathrm{http}: / / \mathrm{www}$. dovepress.com/testimonials.php to read real quotes from published authors. 